\title{
OLA1 is a potential prognostic molecular biomarker for endometrial cancer and promotes tumor progression
}

\author{
YANQI DONG, AIQI YIN, CAIQU XU, HUIPING JIANG, QINGHAI WANG, WENJUAN WU and SUIQUN GUO \\ Department of Obstetrics and Gynecology, The Third Affiliated Hospital of Southern \\ Medical University, Guangzhou, Guangdong 510630, P.R. China
}

Received September 8, 2020; Accepted April 21, 2021

DOI: $10.3892 / 01.2021 .12837$

\begin{abstract}
Obg-like ATPase 1 (OLA1) is upregulated in the tumor tissues in different types of cancer. However, the function of OLA1 and its molecular mechanisms in endometrial cancer (EC) remain unknown. The present study aimed to elucidate OLA1 expression level and its biological function in endometrial cancer. The differential expression of OLA1 between EC tissues and non-cancerous tissues was analyzed using The Cancer Genome Atlas database and clinical samples. The association between clinicopathological characteristics and OLA1 expression was analyzed using bioinformatics analysis. Cell proliferation, migration and invasion were analyzed by short interfering RNA-mediated knockdown experiments, Cell Counting Kit-8, 5-Ethynyl-2'-deoxyuridine incorporation, wound healing, Transwell and Boyden assays. The potential signaling pathways associated with OLA1 in endometrial cancer were evaluated by Gene Set Enrichment Analysis. The expression levels of OLA1 in EC tissues were upregulated compared with that in non-cancerous tissues $(\mathrm{P}<0.001)$. Furthermore, patients with worse survival were found to have higher OLA1 expression, and increased OLA1 expression in endometrial cancer associated with clinical stage $(\mathrm{P}<0.01)$, histological type $(\mathrm{P}<0.01)$, histological grade $(\mathrm{P}<0.01)$, menstrual status $(\mathrm{P}<0.01)$, cancer status $(\mathrm{P}<0.05)$ and distant metastasis $(\mathrm{P}<0.05)$. In RL95-2 and HEC-1B cell lines, decreased levels of OLA1 inhibited proliferation, invasion and migration, and the TGF- $\beta$ signaling pathway, ubiquitin-mediated proteolysis and Wnt signaling pathway may be involved in these mechanisms. The present study revealed that OLA1 could be a potential prognostic indicator and therapeutic target in endometrial cancer, and that the TGF- $\beta$ signaling, Wnt
\end{abstract}

Correspondence to: Professor Suiqun Guo, Department of Obstetrics and Gynecology, The Third Affiliated Hospital of Southern Medical University, 183 Zhongshan Avenue West, Guangzhou, Guangdong 510630, P.R. China

E-mail: guosq2005@126.com

Key words: endometrial cancer, the cancer genome atlas, Obg-like ATPase 1, prognosis, signaling pathway, gene set enrichment analysis signaling and ubiquitin-mediated proteolysis pathways may be regulated by OLA1.

\section{Introduction}

Endometrial cancer (EC) is one of the most common gynecological malignancies in the United States, and the incidence of this disease is increasing $(1,2)$. Epidemiological studies have estimated that 66,570 uterine corpus cancer cases and 12,904 deaths will occur in 2021 (2). The upward trend in the incidence of EC may be attributed to the increasing rate of obesity in most part of the world (3). Although EC is often diagnosed at an early stage, high-grade lesions account for a large proportion of deaths (4). Hamilton et al demonstrated that high-grade EC accounts for only $28 \%$ of all new diagnoses, but $74 \%$ of all EC deaths (5). The main treatment for stage I and II EC is a total hysterectomy and bilateral salpingo-oophorectomy, which is often effective (6,7). However, advanced disease is not curable and chemotherapy remains the main therapy $(8,9)$. These factors reflect a lack of advances in treatment for patients with high-grade EC. Therefore, identifying EC-related genes and developing an improved understanding of their biological function may promote novel breakthroughs for EC treatment.

Obg-like ATPase 1 (OLA1) is ubiquitously expressed in a majority of organisms, including bacteria, plants and humans, and it belongs to the Obg family of P-loop GTPases (10-12). OLA1 is essential to the cellular stress response, heat shock, cell adhesion and the antioxidant response (13-16). Heat shock protein 70 (HSP70) is a key molecule in different types of cancer, and high expression of HSP70 is associated with poor tumor progression. OLA1 regulates HSP70 protein stability to inhibit shock-induced cell death $(14,15)$. In addition, OLA1 downregulates SOD2 by driving the ubiquitin proteasome pathway in persistent pulmonary hypertension of the newborn of lambs (16). Further, OLA1 affects lung cancer growth by binding to GSK3$\beta$ to suppress its expression (17). In breast cancer, OLA1 promotes tumor invasion and metastasis by inhibiting the production of reactive oxygen species (18). Moreover, OLA1 enhances chemotherapy resistance by inhibiting the epithelial-mesenchymal transition process via the TGF- $\beta /$ Smad pathway in breast cancer cells (19). OLA1 also interacts with BRCA1 and BRCA1-associated RING domain protein 1, which affects centrosome function and is suspected to lead to carcinogenesis in hereditary breast and ovarian 
cancer (20-22). These features clearly indicate that OLA1 is an influential gene in different types of adenocarcinoma, yet the biological function of OLA1 in EC has been poorly characterized. Therefore, the present study hypothesized that abnormal OLA1 expression is one of the factors influencing the occurrence and development of EC. To test this proposal, the current study used clinical samples and The Cancer Genome Atlas (TCGA) database to explore the potential biological role and prognostic value of OLA1 in EC, and validated the results using in vitro experiments.

\section{Materials and methods}

TCGA database. The clinical and transcriptome profiling data for uterine corpus endometrial cancer were downloaded from the official TCGA website (https://portal.gdc.cancer.gov) (23). This provided $552 \mathrm{EC}$ samples and 35 non-cancerous samples that were profiled for the differences between non-cancerous tissues and EC tissues, and 23 pairs of matched samples were profiled for the same purpose. In total, discarding the missing data, 510 tumor cases with clinical information were profiled for class discovery and survival analysis. The patients ranged in age from 31-90 years. The complete description of the clinical data is summarized in Table I. Gene Set Enrichment Analysis (GSEA) was used to detect signaling pathways in which genes may be involved in EC. In addition, GSEA (http://www.gsea-msigdb.org/gsea/index.jsp) was used to analyze biological processes and signaling pathways in the transcriptomes of the OLA1 expression samples from TCGA. The gene set database used was c2.cp.kegg.v.6.2.symbols.gmt.

Cell culture. The EC cell lines were purchased from The Cell Bank of Type Culture Collection of The Chinese Academy of Sciences. The cell lines were Ishikawa, RL95-2, HEC-1A and HEC-1B. The Ishikawa cells were maintained in RPMI 1640 medium (Biological Industries), while the others were cultured in DMEM (HyClone; Cytiva). Both were supplemented with $10 \%$ fetal calf serum (Biological Industries). Cells were incubated at a temperature of $37^{\circ} \mathrm{C}$ and a humidified atmosphere of $5 \% \mathrm{CO}_{2}$.

Clinical sample collection. EC and corresponding adjacent endometrial tissue microarrays (cat. no. EMC1351) were purchased from Superbiotek (http://www.superbiotek.com). OLA1 expression was determined by immunohistochemical staining in 135 cases including 118 EC cancer tissues and 17 adjacent tissues.

Immunohistochemistry (IHC) and evaluation of staining. The tissue microarrays were used for immunohistochemistry analysis to evaluate OLA1 protein expression levels in EC. IHC was performed as per our previous study (24). The sections ( $3 \mu$ m-thick) were deparaffinized in $100 \%$ xylene and rehydrated in a descending ethanol series (100, 90, 80 and $70 \%$ ethanol) and antigen retrieval was performed in citrate buffer for $5 \mathrm{~min}$ at $100^{\circ} \mathrm{C}$. The tissue section was incubated with $3 \% \mathrm{H}_{2} \mathrm{O}_{2}$ at $37^{\circ} \mathrm{C}$ for $10 \mathrm{~min}$ to block and inactivate endogenous peroxidase. In order to block non-specific binding sites, the section was incubated with goat serum (ZSGB-Bio Technologies) for $15 \mathrm{~min}$. Subsequently, the section was stained with primary antibody against OLA1 (Table SI) at $4^{\circ} \mathrm{C}$ overnight. In the next day, the section was incubated with a biotin-labeled secondary antibody for $30 \mathrm{~min}$ after re-warming at $37^{\circ} \mathrm{C}$ for $45 \mathrm{~min}$. Horseradish peroxidase-labeled streptomycin avidin working solution was added to the section and incubated for $30 \mathrm{~min}$. $\mathrm{DAB} / \mathrm{H}_{2} \mathrm{O}_{2}$ staining reaction was performed for color development, then the section was counterstained with hematoxylin. The images were captured using a bright field light microscope (magnifications, $x 40$ and x200). For IHC assays, the staining intensity and percentage of positive cells were analyzed. The OLA1 stain index was the product of the intensity $(0$, negative; 1 , weak; 2 , moderate; and 3 , strong) and stain-positive cells $(0,<5 ; 1,5-25 ; 2,26-50$; 3, 51-75; and 4, >75\%) (25). Two pathologists scored the sections while blinded to the patients' information. After scoring, the samples were grouped according to International Federation of Gynecology and Obstetrics (FIGO) stages and then statistical analysis was performed (6).

Cell transfection. Guangzhou RiboBio Co., Ltd. designed and synthesized the small interfering RNA (siRNA) for the OLAl gene (siOLA1) and for the scrambled negative control (NC). The sequences are listed in Table II. OLAl plasmid (ov-OLA1) and empty mock (ov-mock) plasmid were purchased in $\mathrm{OBiO}$ Technology (Shanghai) Corp. (https://www.obiosh.com). Transfection was performed as per our previous study (26). RL95-2 and HEC-1B cells were cultured in six-well plates (Corning, Inc.) at 30-50\% confluence for $24 \mathrm{~h}$ before transfection. Subsequently, $5 \mu$ l Lipofectamine ${ }^{\circledR} 2000$ transfection reagent (Invitrogen; Thermo Fisher Scientific, Inc.) was used to transfect the siRNA $(10 \mu \mathrm{l})$ or plasmid $(2 \mu \mathrm{l})$ into cells at a working concentration of $100 \mathrm{nM}$. Cells were collected for further experiments after 48-72 h. Efficiency of the transfection was quantitatively assessed using reverse transcription-quantitative (RT-q)PCR at $48 \mathrm{~h}$ after transfection, and assessed by western blot at $72 \mathrm{~h}$ after transfection.

RNA isolation, $R T-q P C R$ and primers. RNAiso Plus reagent (Takara Bio, Inc.) was used to extract total RNA from the RL95-2 and HEC-1B cells. Then, total RNA (1 $\mu \mathrm{g})$ was reverse transcribed into complementary DNA, according to the manufacturer's protocol. The reverse transcription reagent kit was purchased from Takara Bio, Inc. The mRNA expression levels were measured using ChamQ Universal SYBR qPCR master mix kit (Vazyme Biotech Co., Ltd.) according to the manufacturer's protocol. The amplification conditions were as follows: 1 cycle of $95^{\circ} \mathrm{C} 30 \mathrm{sec} ; 40$ cycles of $95^{\circ} \mathrm{C} 5 \mathrm{sec}, 60^{\circ} \mathrm{C}$ $30 \mathrm{sec}$; and $95^{\circ} \mathrm{C}$ for $15 \mathrm{sec}$. Relative mRNA expression levels were calculated using the $2^{-\Delta \Delta C q}$ method (27) and normalized to the internal reference gene GAPDH. Specific primer sequences for OLA1 were designed as follows: Sense, 5'-AAAGGTGGC TGTGAGAGGAGGAG-3' and antisense, 5'-TGTGTCATGTTC GCTTCCAGATACTTC-3'. GAPDH was used as the internal control. Specific primer sequences for GAPDH were designed as follows: Sense, 5'-CGCTGAGTACGTCGTGGAGTC-3'; antisense, 5'-GCTGATGATCTTGAGGCTGTTGTC-3'.

Cell proliferation analysis. Cell Counting Kit-8 (CCK-8) assay is widely used in cell proliferation detection, and it is based on WST-8, a compound similar to MTT. When WST-8 is present 
Table I. TCGA characteristics of 510 patients with endometrial cancer.

\begin{tabular}{|c|c|c|}
\hline Clinical characteristics & Value & $\mathrm{n}, \%$ \\
\hline Median age at diagnosis, years (range) & $66(31-90)$ & \\
\hline \multicolumn{3}{|l|}{ Clinical stage (FIGO), $\mathrm{n}$} \\
\hline I & 314 & 61.57 \\
\hline II & 48 & 9.41 \\
\hline III & 120 & 23.53 \\
\hline IV & 28 & 5.49 \\
\hline \multicolumn{3}{|l|}{ Histological grade, $\mathrm{n}$} \\
\hline G1 & 92 & 18.04 \\
\hline $\mathrm{G} 2$ & 116 & 22.75 \\
\hline G3 & 291 & 57.06 \\
\hline High-grade & 11 & 2.16 \\
\hline \multicolumn{3}{|l|}{ Histological type, $\mathrm{n}$} \\
\hline $\begin{array}{l}\text { Endometrioid endometrial } \\
\text { adenocarcinoma }\end{array}$ & 383 & 75.10 \\
\hline Serous endometrial adenocarcinoma & 105 & 20.59 \\
\hline Mixed serous and endometrioid & 22 & 4.31 \\
\hline \multicolumn{3}{|l|}{ Cancer status, $\mathrm{n}$} \\
\hline Tumor-free & 412 & 84.08 \\
\hline With tumor & 78 & 15.92 \\
\hline \multicolumn{3}{|l|}{ Menopause status, $\mathrm{n}$} \\
\hline Pre & 34 & 7.33 \\
\hline Peri & 17 & 3.66 \\
\hline Post & 413 & 89.01 \\
\hline \multicolumn{3}{|l|}{ Body mass index, $\mathrm{n}$} \\
\hline$\geq 29.9$ & 294 & 60.74 \\
\hline$<29.9$ & 190 & 39.26 \\
\hline \multicolumn{3}{|l|}{ Surgical approach, $\mathrm{n}$} \\
\hline Open & 296 & 60.66 \\
\hline Minimally invasive & 192 & 39.34 \\
\hline \multicolumn{3}{|l|}{ Lymph nodes, $\mathrm{n}$} \\
\hline Negative & 270 & 79.89 \\
\hline Positive & 68 & 20.11 \\
\hline \multicolumn{3}{|l|}{ Distant metastasis, $\mathrm{n}$} \\
\hline Negative & 482 & 94.51 \\
\hline Positive & 28 & 5.49 \\
\hline
\end{tabular}

in 1-methoxy-5-methylphenazinium dimethyl sulfate, it can be reduced into formazan, a highly water-soluble product that is yellow. The color turns darker when the proliferation rate increases. Namely, the color depth is proportional to the number of living cells. Thus, this characteristic makes it a good choice for analyzing cells proliferation. RL95-2 and HEC-1B cells transfected with siNC, siOLA1-1 and siOLA1-3 were seeded at 1,000 cells per well in 96-well microplates (Corning, Inc.). CCK-8 (Dojindo Molecular Technologies, Inc.) was used to measure cell viability. The cells were cultured for 1-3 or 4 days before detection. The OD value was measured at a wavelength of $450 \mathrm{~nm}$, using a microplate reader (BioTek Instruments, Inc.). All assays were repeated three times.
Table II. Target sequences of siRNA used in this study.

\begin{tabular}{lc}
\hline siRNA & Sequence, 5'-3' $^{\prime}$ \\
\hline siOLA1-1 & GTGCTTTGGTCATTCCTTT \\
siOLA1-2 & GTTCGCTTCTATCATGATT \\
siOLA1-3 & CTACTTGGTTAATCTTTCT
\end{tabular}

si, short interfering; OLA, Obg-like ATPase 1.

5-Ethynyl-2'-deoxyuridine (EdU) incorporation. EdU, an analogue of thymidine, can take the replace of thymine $(\mathrm{T})$ in the DNA during cell proliferation. In other words, when the cell cycle changes from the $\mathrm{G}$ phase to $\mathrm{S}$ phase, EdU can be used as a substitute for $\mathrm{T}$ to incorporate DNA. Based on the incorporation of EdU and Apollo ${ }^{\circledR}$ fluorescence, it can detect the DNA replication activity of cells can quickly and accurately. The Cell-Light ${ }^{\mathrm{TM}}$ EdU Apollo ${ }^{\circledR} 567$ in vitro imaging kit (cat. no. C10310-1, Guangzhou RiboBio Co., Ltd.) was used to examine proliferating cells. RL95-2 and HEC-1B cells transfected with siNC, siOLA1-1 and siOLA1-3 were cultured at 2,000 cells per well in 96-well microplates for $12 \mathrm{~h}$. When the cells were in the logarithmic proliferation phase, the medium was changed to a prepared EdU medium (cat. no. C10310-1, Guangzhou RiboBio Co., Ltd.) and incubated for $2 \mathrm{~h}$. To preserve the cellular structure, the cells were incubated $4 \%$ paraformaldehyde at room temperature for $30 \mathrm{~min}$. After decolorization for $5 \mathrm{~min}$ with $2 \mathrm{mg} / \mathrm{ml}$ of glycine and PBS solution, the cells were permeabilized in $0.5 \%$ Triton X-100 for $10 \mathrm{~min}$ at $25^{\circ} \mathrm{C}$. Finally, all the cells were stained with Apollo ${ }^{\circledR} 567$ dye solution for $30 \mathrm{~min}$ and $5 \mu \mathrm{g} / \mathrm{ml}$ of DAPI for $10 \mathrm{~min}$ at $25^{\circ} \mathrm{C}$ in dark. PBS was used to wash the cells.

Wound healing assay. RL95-2 and HEC-1B cells were inoculated in six-well plates for overnight adherence until they were $90 \%$ confluent, and they were scratched by scraping the confluent cell monolayers with a pipette tip. The cells were washed with PBS three times and incubated in serum-free medium. Images of cell migration images were captured using a light microscope at different time points $(0,24,48$ and $72 \mathrm{~h}$ ). Scratch widths were recorded to compare the healing rate. The experiments and assays were repeated at least three times.

Migration and invasion assays. The migration and invasion of tumor cells were detected by Transwell and Boyden experiments utilizing a Transwell apparatus (Corning, Inc.). A total of $100 \mu \mathrm{l}$ of $1 \times 10^{5}$ cells mixed with serum-free DMEM medium (HyClone; Cytiva). were seeded in the wetted top chamber. Then, $500 \mu \mathrm{l}$ of DMEM containing $10 \%$ FBS in the bottom chamber attracted cellular migration and invasion. For the Boyden assay, Matrigel (R\&D Systems, Inc.) was precoated for $6 \mathrm{~h}$ in the top chamber at $37^{\circ} \mathrm{C}$. After incubation at $37^{\circ} \mathrm{C}$ in $5 \% \mathrm{CO}_{2}$ for $10 \mathrm{~h}$ (for the Transwell assay) or $20 \mathrm{~h}$ (for the Boyden assay), the cells were stained with crystal violet solution at $25^{\circ} \mathrm{C}$ for $5 \mathrm{~min}$, and the non-migrated cells were removed with a cotton swab. Images of five fields were 
randomly captured under a light microscope (magnification, x100).

Western blot analysis. Western blot analysis was performed as previously described (26). Antibodies used included anti-OLA1, GAPDH, Smad 3, Smad 4, p-GSK3 $\beta$ and $\beta$-catenin. The antibodies, dilutions and suppliers are listed in Table SI. The secondary antibody used was horseradish peroxidase-conjugated anti-mouse and anti-rabbit immunoglobulin-G antibody (both 1:3,000 dilution; CoWin Biosciences). GAPDH was considered a loading control. Blots were detected using enhanced chemiluminescence reagents (Pierce; Thermo Fisher Scientific, Inc.). Protein expression levels were quantified using ImageJ software (version 1.51; National Institutes of Health).

Statistical analysis. R software (version 3.6.1) with the edgeR, glmnet, survivalROC and gplot packages were used to analyze the data from TCGA database (28). GraphPad Prism version 8.1.1 (GraphPad Software, Inc.) software was used for statistical analysis. $\mathrm{P}<0.05$ was considered to indicate a statistically significant difference. 510 EC samples with both OLA1 mRNA expression and clinical information were downloaded from TCGA in January 2020. The high and low expression OLA1 level groups were bounded by the median expression value of OLA1. Wilcoxon rank sum and Wilcoxon signed-rank tests were used to analyze the differences in OLA1 expression levels. Kaplan-Meier analysis was performed to analyze the association between overall survival of patients and OLA1 expression. In addition, the area under the curve (AUC) values of the receiver operating characteristic (ROC) curves were calculated using time-dependent ROC analysis. Univariate logistic regression was used to analyze the association between OLA1 expression and clinicopathological characteristics. Univariate and multivariate Cox regression analyses were performed to analyze the association between clinicopathological characteristics and overall survival of patients. Data are presented as the mean \pm standard deviation (unless otherwise shown). Comparisons between the two groups were performed using unpaired Student's t-tests, while one-way ANOVA was used for multiple groups. Dunnett's and Tukey's post hoc tests were used following ANOVA as appropriate.

\section{Results}

OLA1 expression in EC samples and non-cancerous samples. To investigate whether OLA1 expression is associated with EC progression, publicly available data was downloaded from TCGA database and analyzed. Significant OLA1-upregulation was found in $552 \mathrm{EC}$ samples compared with 35 non-cancerous samples $(\mathrm{P}<0.001$; Fig. 1A). Furthermore, among the matched samples, OLA1 expression levels were also significantly upregulated $(\mathrm{P}<0.001$; Fig. 1B). OLA1 expression levels were further examined by immunostaining human $\mathrm{EC}$ and normal adjacent tissues to verify the results. It was found that OLA1 protein expression levels were markedly higher in stage I $(n=98)$, stage II $(n=12)$ and stage III $(n=8)$ tissues compared with that of normal adjacent tissues $(n=13)$ (all, $\mathrm{P}<0.001$; Fig. 1C). Taken together, these results suggest that OLA1 expression is strongly associated with EC progression.
Associations between clinical characteristics and OLAI expression in the TCGA cohort. In TCGA cohort, the median age at the time of diagnosis was 66 years (range, 31-90 years). The median follow-up time was 33.01 months, and 87 patients died during the follow-up period. Clinical stage, histological grade, histological type, cancer status, body mass index (BMI), surgical approach, lymph node metastasis, menopause status and distant metastasis data in the cohort are shown in Table II. In the cohort, the histological grade included G1 (18\%; n=92), G2 (22.7\%; n=116), G3 (57.1\%; n=291) and high-grade $(2.2 \% ; \mathrm{n}=11)$. FIGO stage included stage I $(61.6 \%$; $\mathrm{n}=314)$, stage II $(9.4 \% ; \mathrm{n}=48)$, stage III $(23.5 \% ; \mathrm{n}=120)$ and stage IV $(5.5 \%$; $n=28)$. Of the histological types in the cohort, endometrioid endometrial adenocarcinoma was found to be the most common $(75.1 \%$; $n=383)$, and other types included mixed serous and endometrioid adenocarcinoma $(4.3 \% ; n=22)$ and serous endometrial adenocarcinoma (20.6\%; $n=105)$. Menopause status included $413(89 \%)$ post-menopause (prior bilateral ovariectomy or $>12$ months since last menstrual period with no prior hysterectomy), 17 (3.7\%) peri-menopause (6-12 months since last menstrual period) and $34(7.3 \%)$ pre-menopause $(<6$ months since last menstrual period and no prior bilateral ovariectomy nor estrogen replacement). Cancer status included 412 patients who were tumor-free $(84.3 \%)$ and 78 patients with tumors (15.7\%). There were $60.7 \%$ who adopted an open surgical approach and $39.3 \%$ who adopted a minimally invasive surgical approach. Of 338 cases, $68(20.1 \%)$ had lymph node metastasis and $28(5.5 \%)$ had distant metastasis. Upregulated OLA1 expression levels were found to be associated with FIGO stage, histological type, histological grade, menopause status, distant metastasis and cancer status (all $\mathrm{P}<0.05$; Fig. 2A-F). Univariate logistic regression showed that high OLA1 expression levels were associated with clinical stage (I vs. II, I vs. IV), histological grade (G1 vs. G2, G1 vs. G3), histological type (EEA vs. SEA), cancer status, lymph node metastasis and distant metastasis in EC (Table III). Collectively, these results suggest that OLA1 expression is associated with clinical characteristics in TCGA cohort.

Prognostic significance of OLAl expression. To evaluate the prognostic significance of OLA1 in EC, the relationship between OLA1 expression and survival time was analyzed. Kaplan-Meier analysis showed that high OLA1 expression had poorer overall survival (OS) time compared with the low OLA1 expression group ( $\mathrm{P}<0.001$; Fig. $2 \mathrm{G})$. Univariate Cox regression analysis showed that age, OLA1 expression, distant metastasis, lymph node metastasis, cancer status, histological grade, histological type and clinical stage were associated with EC prognosis in terms of OS time (all $\mathrm{P}<0.05$; Table IV). Moreover, multivariate analysis revealed that OLA1 expression remained independently associated with OS time (hazard ratio=2.08; $\mathrm{P}<0.05$; Fig. 2I), along with cancer status, histological grade and surgical approach (all, $\mathrm{P}<0.05$; Fig. 2I; Table IV). The AUC was 0.834, reflecting that the prognostic marker model had high sensitivity and specificity in predicting patient survival status (Fig. 2H). Taken together, these results suggest that high OLA1 expression can predict poor survival of patients. 
A

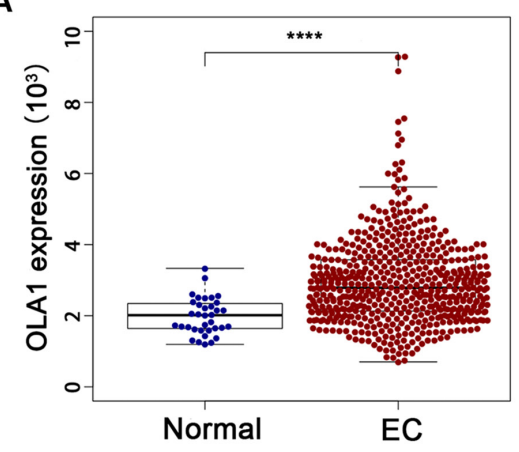

B

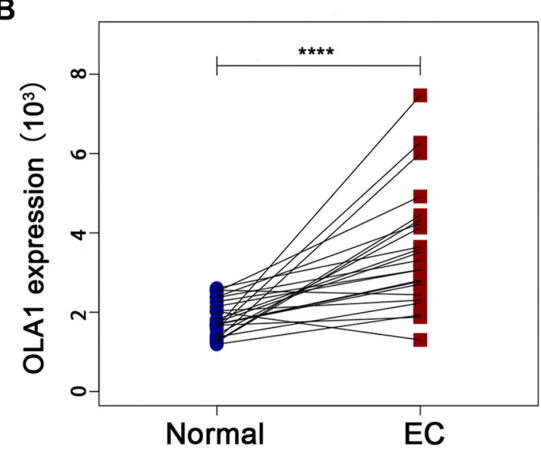

C

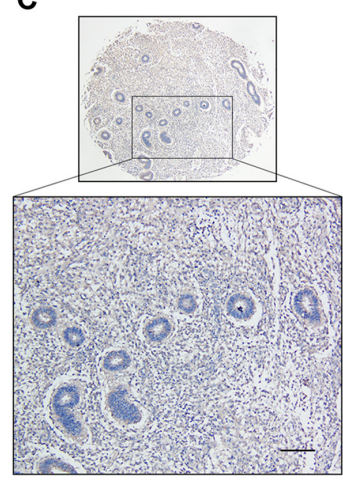

Adjacent tissue

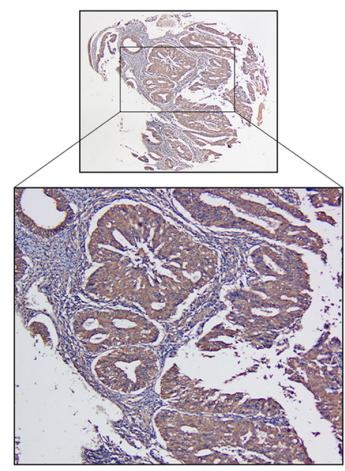

Stage II

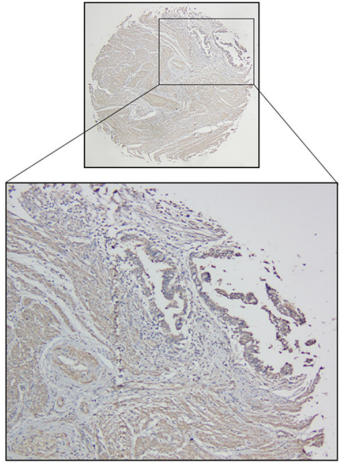

Stage I

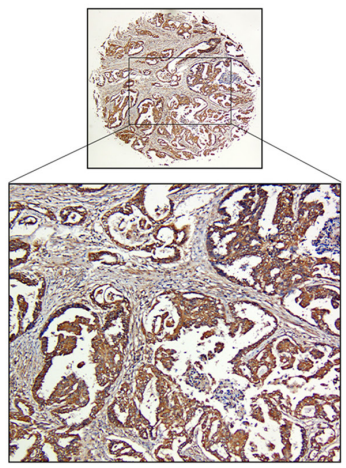

Stage III

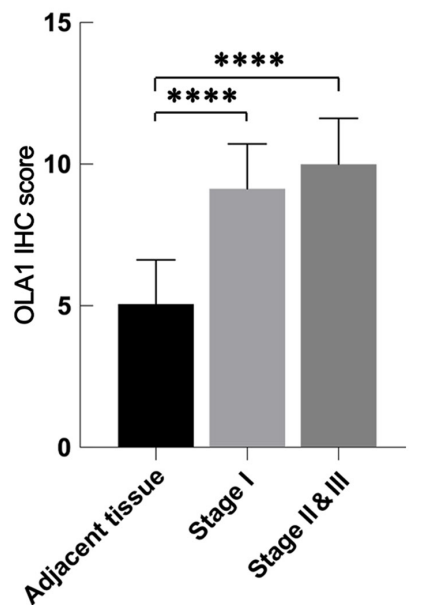

Figure 1. OLA1-upregulation in endometrial cancer samples. (A) OLA1 mRNA expression in 552 tumor samples and 35 normal samples from The Cancer Genome Atlas database. (B) OLA1 mRNA expression in 23 paired samples (normal and tumor samples). (C) OLA1 immunohistochemistry staining in normal and stage I-III tissues. Representative images of OLA1 are shown on the left. Right panel shows OLA1 scores quantified by immunohistochemistry in normal and stage I-III tissues. Scale bar, 2 mm. ${ }^{* * * *} \mathrm{P}<0.0001$. OLA1, Obg-like ATPase 1; EC, endometrial cancer.

Knockdown of OLAl expression suppresses cell proliferation in EC. To explore the expression level of OLA1 in EC cells, the RL95-2, Ishikawa, HEC-1B and HEC-1A cell lines were cultured, then endogenous OLA1 expression levels were analyzed using RT-qPCR and western blotting. The results suggested that the levels of OLA1 expression were higher in the RL95-2 and HEC-1B lines compared with the Ishikawa and HEC-1A. Therefore, HEC-1B and RL95-2 lines were selected for subsequent experiments (Fig. 3A and B). To characterize the effect of OLA1 expression on EC cells, three siRNAs were designed to specifically target OLA1 (siOLA1) to knockdown OLA1 expression. The cells transfected with siOLA1-1 and
siOLA1-3 were selected for subsequent experiments due to their more efficient transfections (Fig. 3C and D).

CCK- 8 assays showed that cells transfected with siOLA1-1 and siOLA1-3 had a significantly decreased proliferative capacity ( $\mathrm{P}<0.01$; Fig. $3 \mathrm{E})$, while OLA1-overexpression enhanced cell proliferation ( $\mathrm{P}<0.01$; Fig. S1). EdU incorporation assays revealed that there were fewer cells that had been transfected with OLA1 siRNAs in the S phase compared with cells transfected with the siNC, suggesting that endogenous OLA1 promotes EC cell proliferation (Fig. 3F). Collectively, these results suggest that low OLA1 expression suppresses EC cell proliferation. 

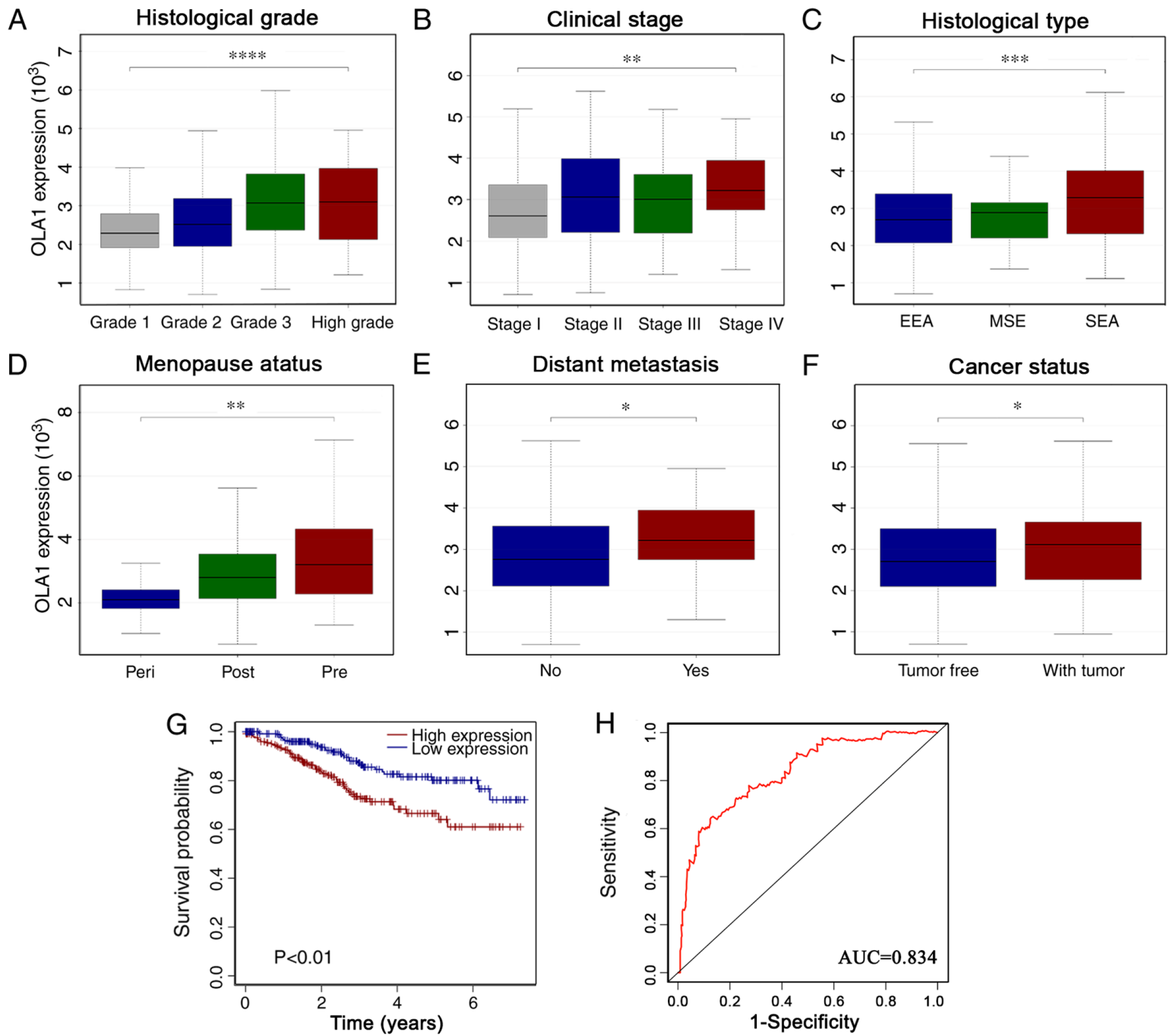

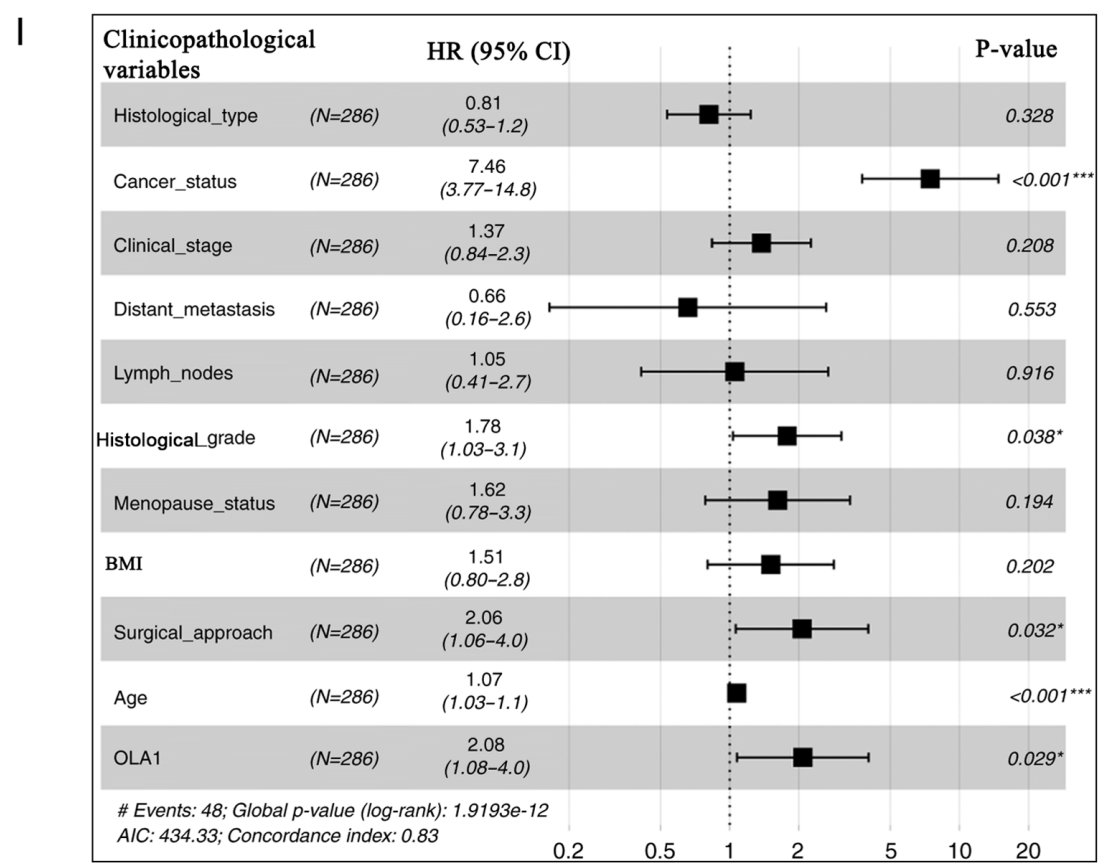

Figure 2. Clinicopathological features of OLA1 expression. OLA1 expression upregulation was associated with clinicopathological characteristics, including (A) histological grade, (B) clinical stage, (C) histological type, (D) menopause status, (E) distant metastasis and (F) cancer status. (G) Kaplan-Meier survival analysis of patients with endometrial cancer from The Cancer Genome Atlas cohort based on OLA1 expression. (H) Receiver operating characteristic curves for Cox analysis. Variables included histological grade, clinical stage, histological type, menopause status, distant metastasis, body mass index, surgical approach and OLA1 expression. (I) Multivariate survival analysis of the clinicopathological characteristics of patients with EC. ${ }^{*} \mathrm{P}<0.05,{ }^{* * *} \mathrm{P}<0.01,{ }^{* * * *} \mathrm{P}<0.001$ and ${ }^{* * * * *} \mathrm{P}<0.0001$. OLA1, Obg-like ATPase 1; EC, endometrial cancer; AUC, area under the curve; BMI, body mass index. 
Table III. OLA1 expression associated with clinicopathological characteristics (logistic regression).

\begin{tabular}{|c|c|c|c|}
\hline Clinical characteristics & Total, n & Odds ratio in OLA1 expression $(95 \%$ CI) & P-value \\
\hline Age, continuous & 509 & $1.01(0.99-1.02)$ & 0.479 \\
\hline \multicolumn{4}{|l|}{ Clinical stage (FIGO) } \\
\hline I vs. II & 362 & $2.1(1.13-3.99)$ & 0.020 \\
\hline I vs. III & 434 & $1.49(0.98-2.28)$ & 0.065 \\
\hline I vs. IV & 342 & $3.78(1.63-9.82)$ & 0.003 \\
\hline \multicolumn{4}{|l|}{ Histological grade } \\
\hline G1 vs. G2 & 208 & $2.19(1.22-4.04)$ & 0.010 \\
\hline G1 vs. G3 & 383 & $4.66(2.79-8.03)$ & $<0.001$ \\
\hline G1 vs. high-grade & 103 & $3.60(1.00-13.58)$ & 0.493 \\
\hline \multicolumn{4}{|l|}{ Histological type } \\
\hline EEA vs. MSE & 405 & $1.79(0.75-4.43)$ & 0.191 \\
\hline EEA vs. SEA & 488 & $2.59(1.65-4.12)$ & $<0.001$ \\
\hline Cancer status, tumor-free vs. with tumor & 490 & $1.99(1.21-3.32)$ & 0.007 \\
\hline \multicolumn{4}{|l|}{ Menopause status } \\
\hline Post vs. Peri & 430 & $0.21(0.05-0.66)$ & 0.016 \\
\hline Post vs. Pre & 447 & $1.59(0.79-3.34)$ & 0.204 \\
\hline Body mass index, $<29.9$ vs. $\geq 29.9$ & 484 & $1.47(1.02-2.11)$ & 0.041 \\
\hline Surgical approach, open vs. mini-invasive & 488 & $1.46(1.02-2.11)$ & 0.042 \\
\hline Lymph nodes, negative vs. positive & 338 & $1.82(1.06-3.17)$ & 0.031 \\
\hline Distant metastasis, negative vs. positive & 510 & $3.18(1.39-8.20)$ & 0.009 \\
\hline
\end{tabular}

EEA, endometrioid endometrial adenocarcinoma; MSE, mixed serous and endometrioid; SEA, serous endometrial adenocarcinoma; C1, confidence interval.

Table IV. Associations with overall survival and clinicopathological characteristics in patients from The Cancer Genome Atlas using univariate and multivariate cox regression analysis.

\begin{tabular}{|c|c|c|c|c|}
\hline \multirow[b]{2}{*}{ Clinicopathological variables } & \multicolumn{2}{|c|}{ Univariate analysis } & \multicolumn{2}{|c|}{ Multivariate analysis } \\
\hline & HR $(95 \% \mathrm{CI})$ & P-value & $\operatorname{HR}(95 \% \mathrm{CI})$ & P-value \\
\hline Body mass index, $<29.9$ vs. $\geq 29.9$ & $0.98(0.56-1.74)$ & 0.951 & & \\
\hline Clinical stage (FIGO), I vs. II vs. III vs. IV & $1.82(1.41-2.35)$ & $<0.001$ & & \\
\hline Histological type & $1.68(1.25-2.28)$ & 0.001 & & \\
\hline Menopause status, post vs. peri vs. pre & $0.83(0.47-1.48)$ & 0.535 & & \\
\hline Distant metastasis, negative vs. positive & $3.33(1.42-7.85)$ & 0.006 & & \\
\hline Lymph nodes, negative vs. positive & $3.17(1.76-5.70)$ & $<0.001$ & & \\
\hline Surgical approach, open vs. mini invasive & $1.20(0.67-2.16)$ & 0.543 & & \\
\hline Age, continuous & $1.04(1.01-1.07)$ & 0.005 & & \\
\hline Cancer status, tumor free vs. with tumor & $7.13(4.03-12.62)$ & $<0.001$ & $7.46(3.77-14.77)$ & $<0.001$ \\
\hline Histological grade, G1 vs. G2 vs. G3 vs. high-grade & $2.46(1.58-3.85)$ & $<0.001$ & $1.78(1.03-3.06)$ & 0.038 \\
\hline OLA1 expression, low vs. high & $2.32(1.27-4.23)$ & 0.006 & $2.08(1.08-4.02)$ & 0.029 \\
\hline
\end{tabular}

HR, hazard ratio; CI, confidence intervals.

Decreased OLA1 expression inhibits tumor migration and invasion in EC. To identify the effect of OLA1 on the migration and invasion of EC cells, wound healing, Transwell and Boyden assays were performed. Wound healing ability was significantly reduced in the siOLA1-1 and siOLA1-3 groups compared with the siNC group in both the RL95-2 and HEC-1B lines (all $\mathrm{P}<0.05$ Fig. 4A). In addition, the Transwell and Boyden assays showed that cell migration and invasion ability was reduced in the siOLA1 groups compared with the siNC cells (all $\mathrm{P}<0.05$ Fig. $4 \mathrm{~B}$ and $\mathrm{C}$ ). The results suggested 
A
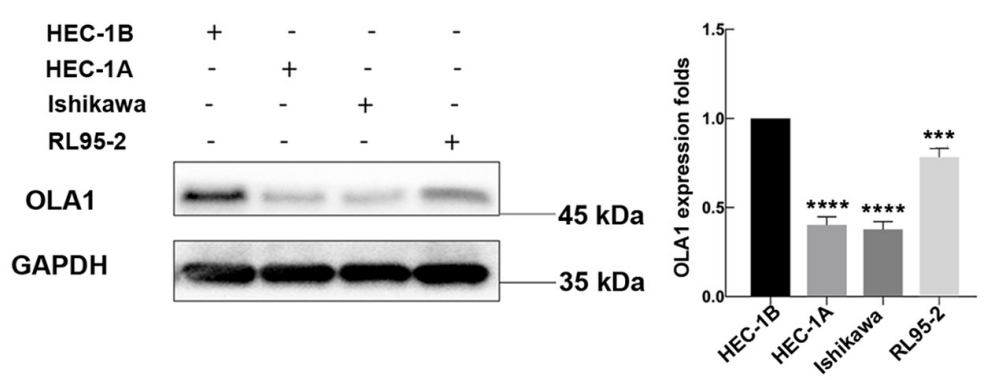

C sinc

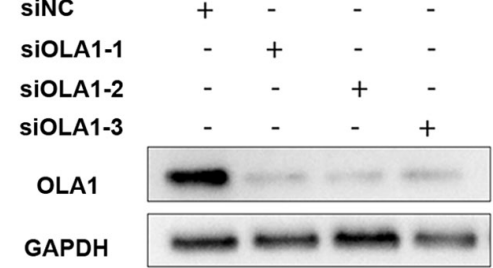

RL95-2

D

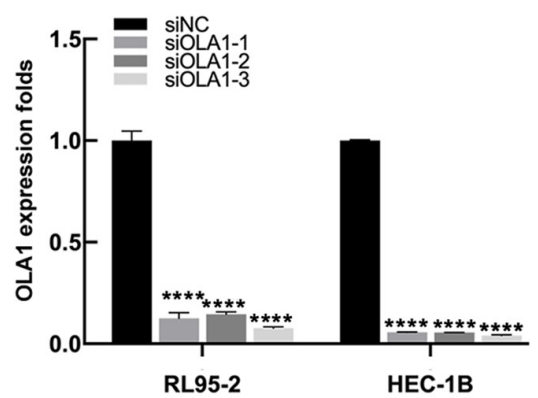

E

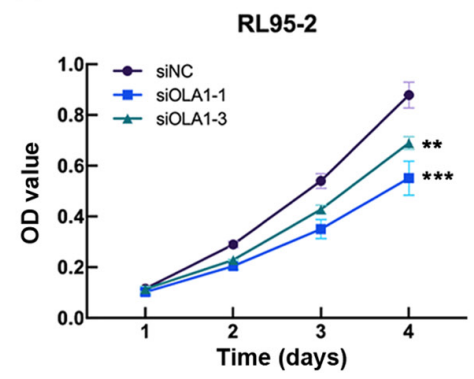

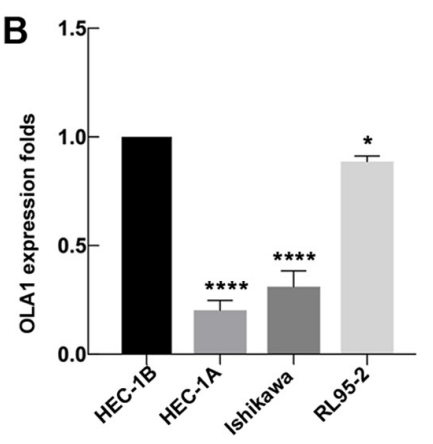

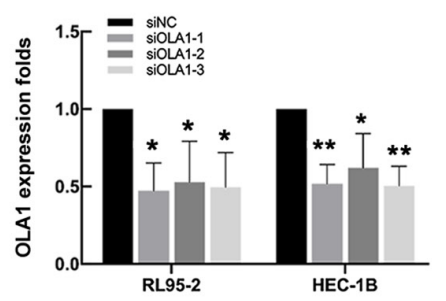

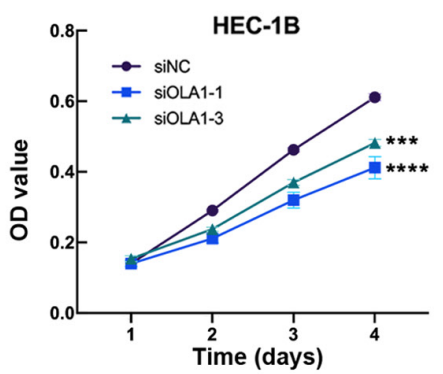

$\mathbf{F}$

siNC

siOLA1-1

siOLA1-3
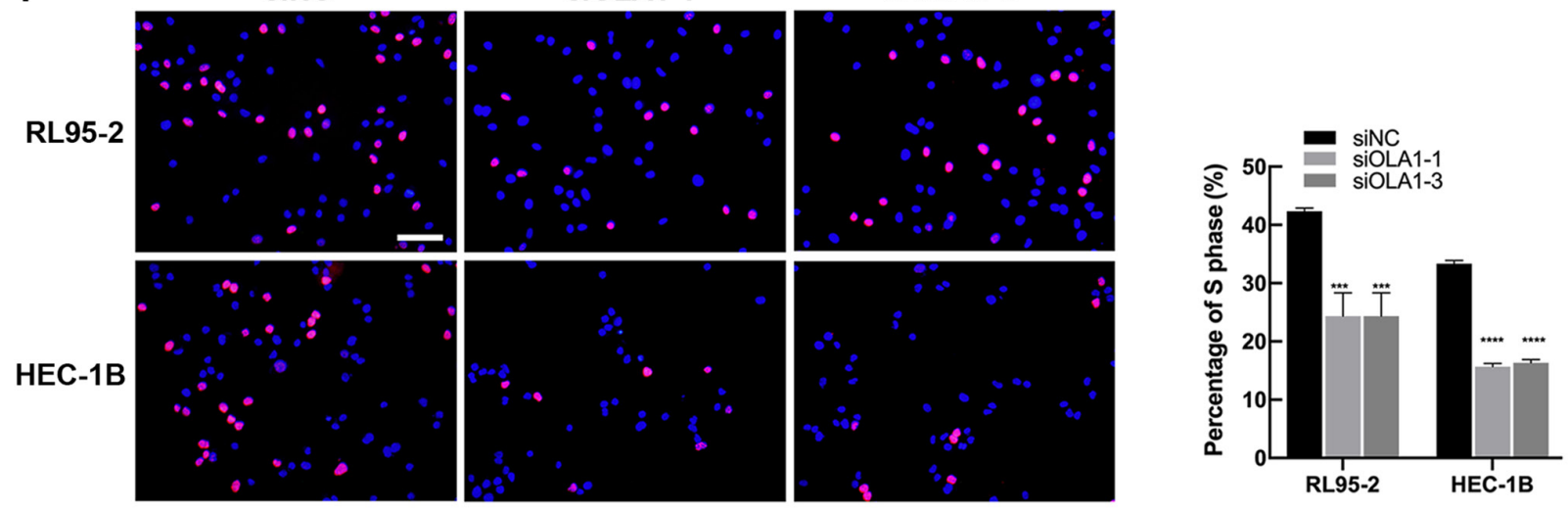

Figure 3. Decreased OLA1 expression inhibits endometrial cancer cell proliferation. (A) Western blot analysis and (B) RT-qPCR showed that OLA1 was highly expressed in the RL95-2 and HEC-1B cell lines. RL95-2 and HEC-1B cells were transfected with siNC, siOLA1-1, siOLA1-2 and siOLA1-3 for $48 \mathrm{~h}$ or $72 \mathrm{~h}$ and then analyzed by (C) western blot analysis (left panel), densitometry analysis (right panel) and (D) RT-qPCR. (E) Cell Counting Kit-8 assays and (F) 5-ethynyl-2'-deoxyuridine incorporation assays of RL95-2 and HEC-1B cells were performed after transfection with siNC, siOLA1-1 and siOLA1-3 (scale bar, $400 \mu \mathrm{m}$ ). ${ }^{*} \mathrm{P}<0.05,{ }^{* *} \mathrm{P}<0.01,{ }^{* * * *} \mathrm{P}<0.001$ and $^{* * * * *} \mathrm{P}<0.0001$ compared with HEC-1B or siNC. OLA1, Obg-like ATPase 1; RT-qPCR, reverse transcription-quantitative PCR; si-, short interfering; NC, negative control.

that knockdown of endogenous OLA1 inhibited EC cell migration and invasion. The findings above decreased OLA1 expression inhibits tumor migration and invasion in EC.

Identification of OLA1-related pathways in EC. To investigate the potential OLA1-related mechanisms in EC,
GSEA was conducted between low and high OLA1 expression datasets. GSEA suggested that high expression of OLA1 may be involved in the 'TGF- $\beta$ signaling pathway' (Fig. 5A), the 'cell cycle; (Fig. 5B), "ubiquitin-mediated proteolysis' (Fig. 5C), the 'p53 signaling pathway' (Fig. 5D), the 'Wnt signaling pathway' (Fig. 5E) and other 

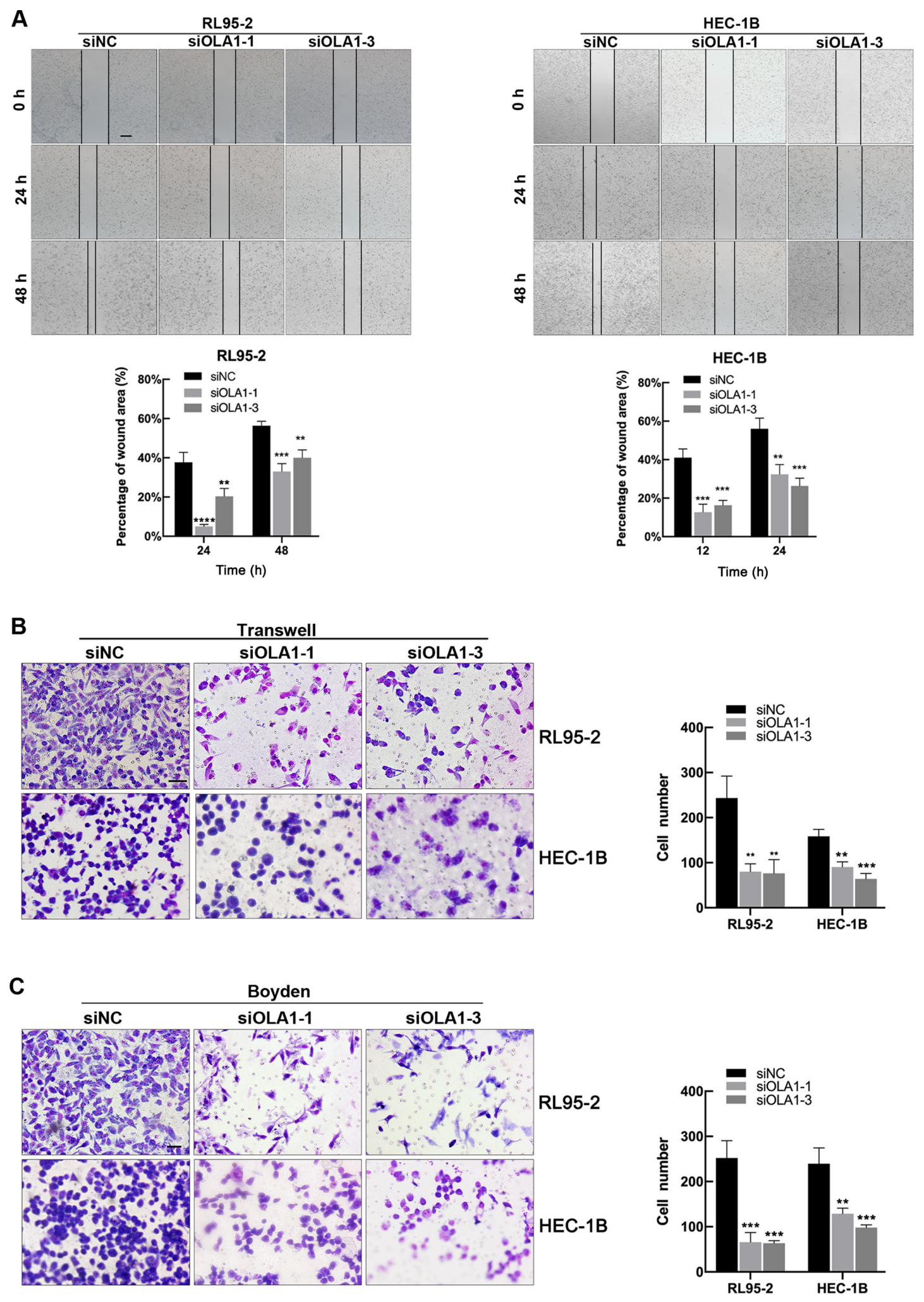

Figure 4. Knockdown of OLA1 expression suppresses endometrial cancer cell migration and invasion. (A) wound healing assays (scale bar, $500 \mu \mathrm{m}$ ), (B) Migration assays (scale bar in RL95-2, $800 \mu \mathrm{m}$; scale bar in HEC-1B, $400 \mu \mathrm{m}$ ) and (C) invasion assays (scale bar in RL95-2, 800 $\mu \mathrm{m}$; scale bar in HEC-1B, $400 \mu \mathrm{m}$ ) of the RL95-2 and HEC-1B cell lines were performed after transfection with siNC, siOLA1-1 and siOLA1-3. ${ }^{* *} \mathrm{P}<0.01,{ }^{* * * *} \mathrm{P}<0.001$ and ${ }^{* * * *} \mathrm{P}<0.0001$ compared with siNC. OLA1, Obg-like ATPase 1; si-, short interfering; NC, negative control.

cancer-related pathways (Fig. 5F). Furthermore, it was found that knockdown of OLA1 significantly suppressed TGF- $\beta$ signaling pathway marker proteins (Smad 3 and 4 ), and $\mathrm{Wnt} / \beta$-catenin signaling pathway marker protenins (GSK3 $\beta$, phosporylated-GSK3 $\beta$ and $\beta$-catenin) (Fig. 5G and $\mathrm{H}$ ). Taken together, these results suggest that the TGF- $\beta$ and Wnt $/ \beta$-catenin signaling pathways may be important pathways regulated by OLA1 in EC. 

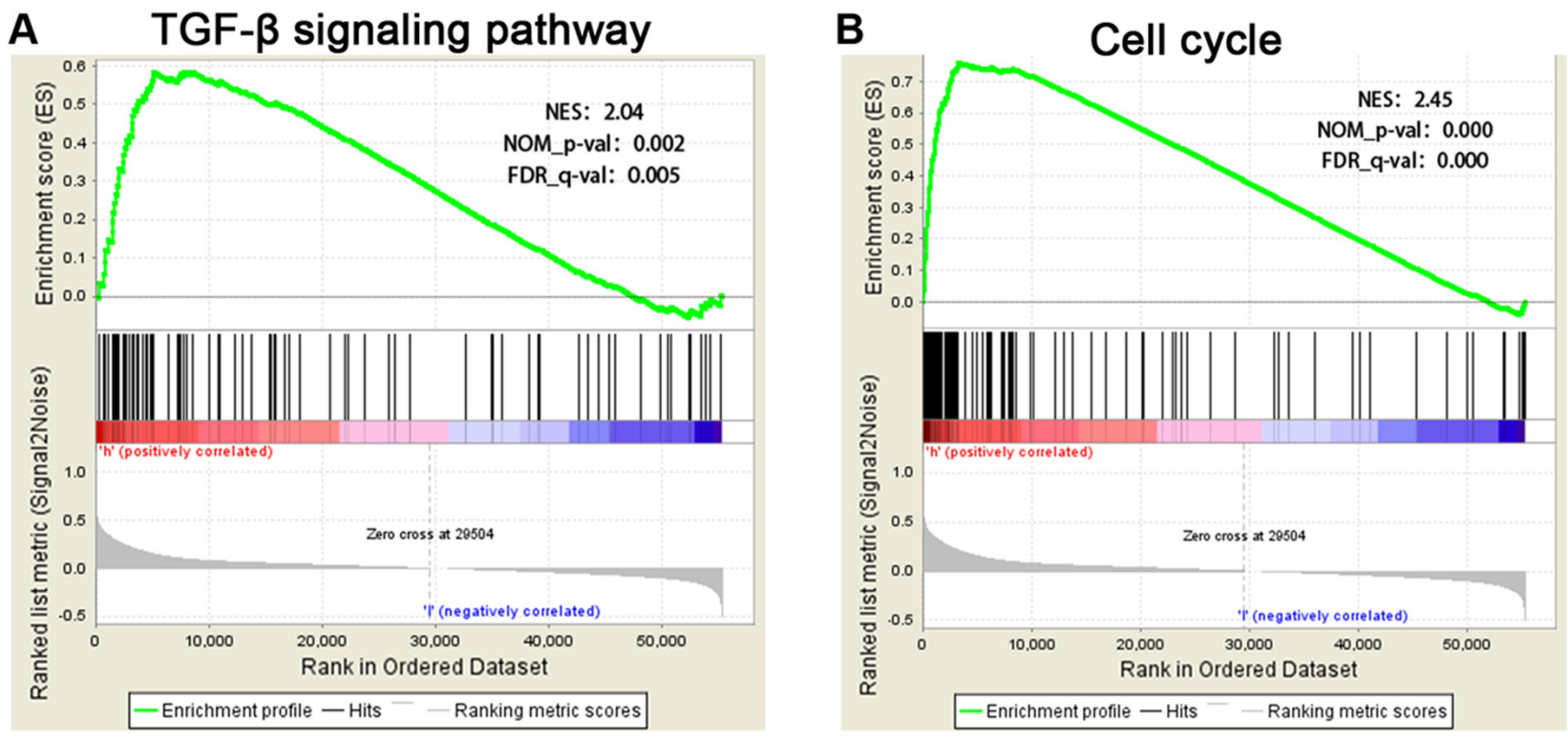

\section{Ubiquitin mediated proteolysis}

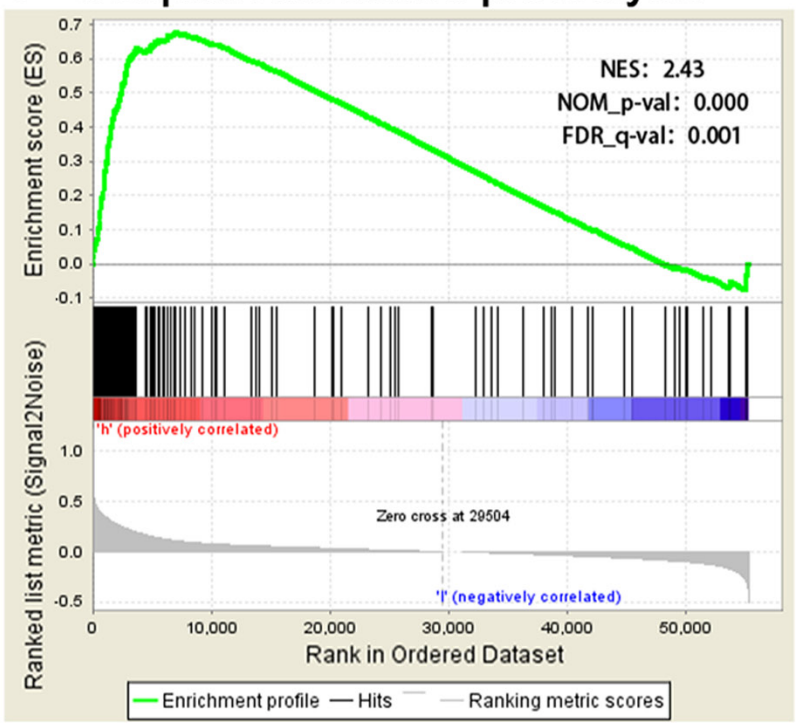

\section{P53 signaling pathway}

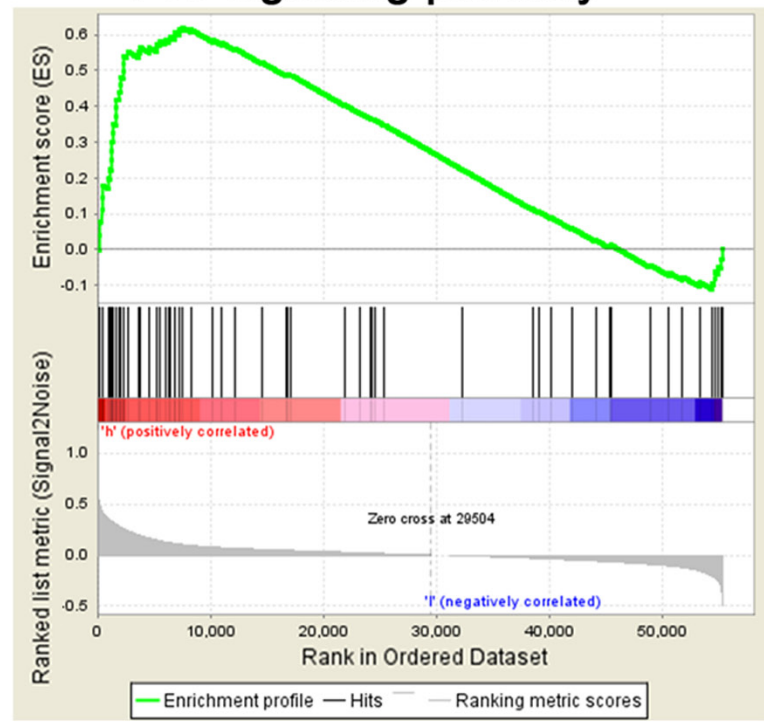

\section{E Wnt signaling pathway}
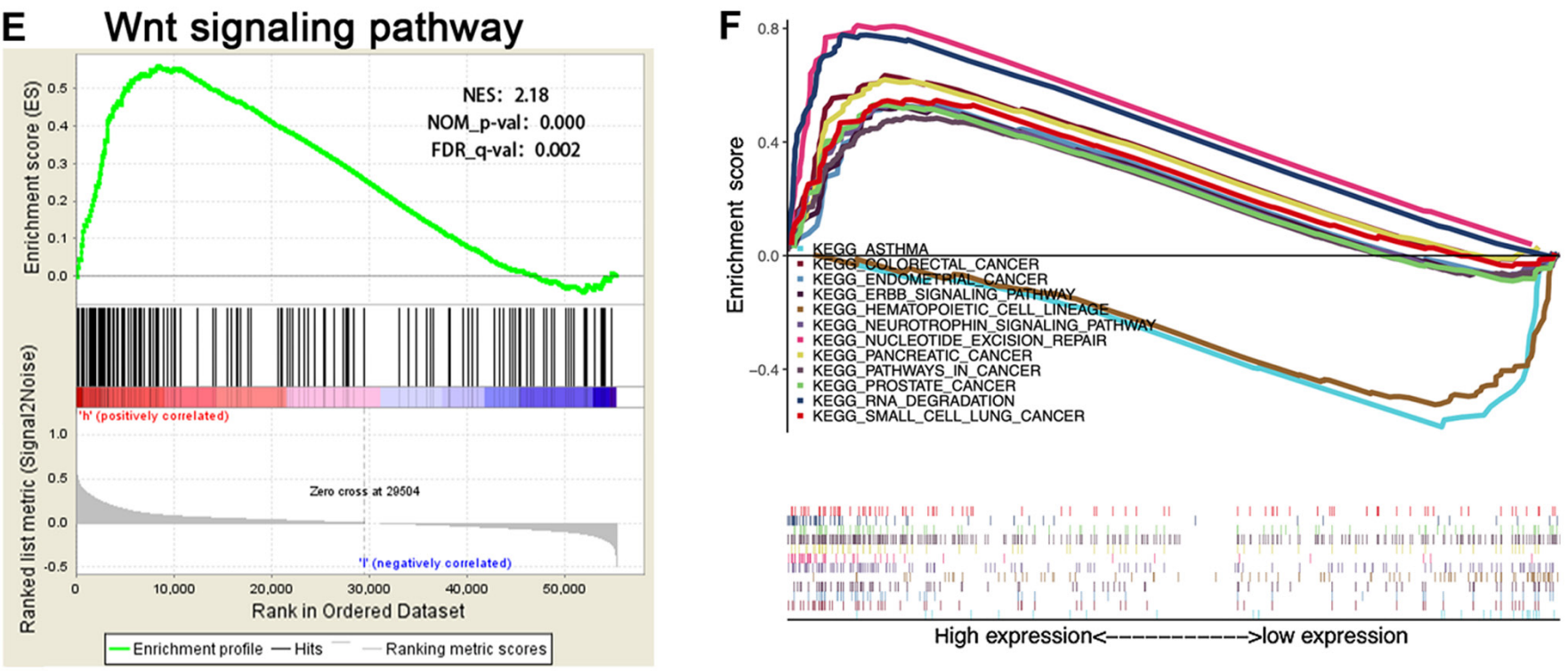

High expression<---------->>low expression 

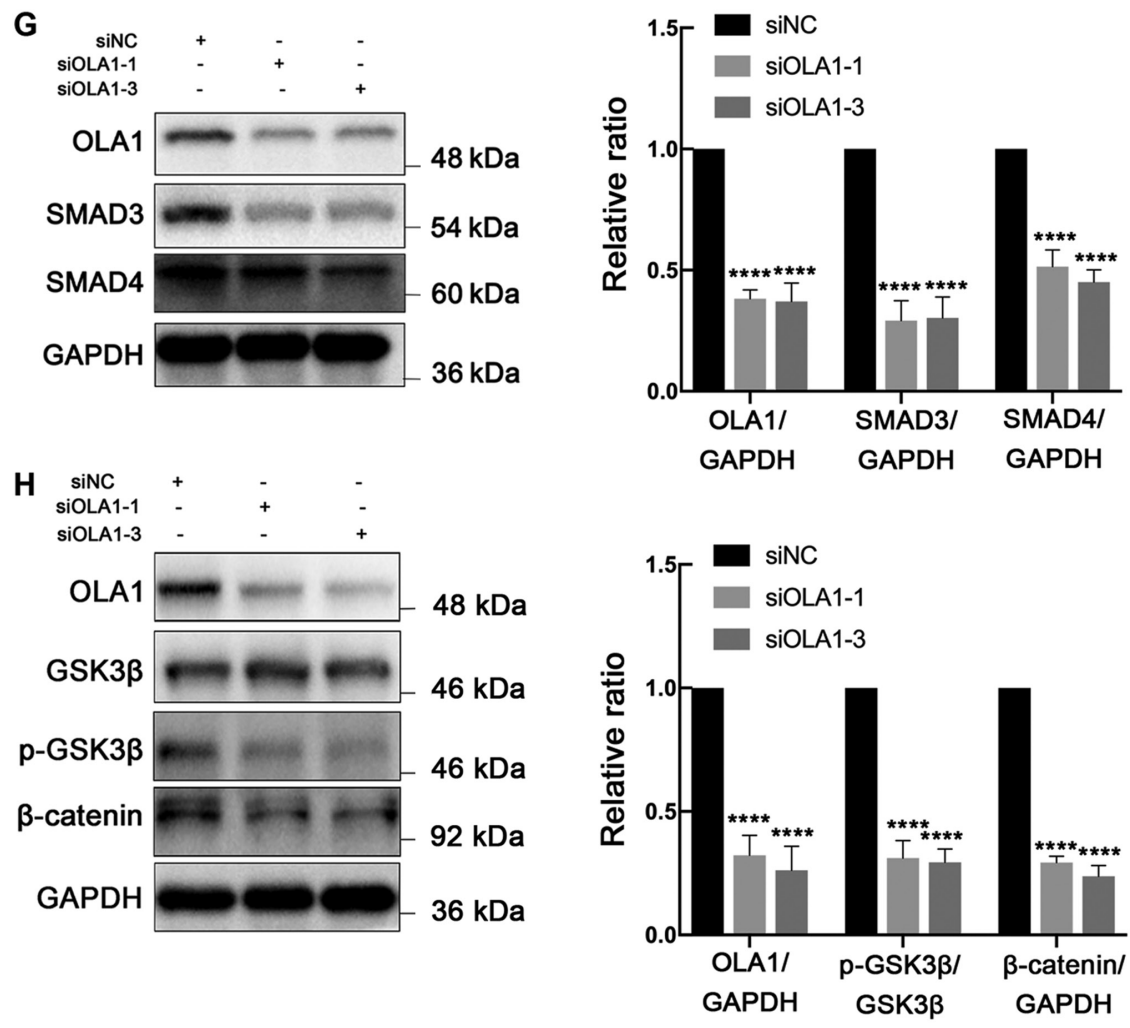

Figure 5. Enrichment plots from the GSEA database. GSEA showed that the (A) 'TGF- $\beta$ signaling pathway', (B) the 'cell cycle', (C) 'ubiquitin-mediated proteolysis', (D) the 'p53 signaling pathway', (E) the 'Wnt signaling pathway' and (F) other pathways were differentially enriched in OLA1-related endometrial cancer. (G) Suppressing OLA1 expression decreased the expression of TGF- $\beta$ maker genes (SMAD3 and SMAD4). (H) Knockdown of OLA1 suppressed expression of GSK3 $\beta$, phosporylated-GSK3 $\beta$ and $\beta$-catenin. ${ }^{* * * * *} \mathrm{P}<0.0001$ compared with siNC. GSEA, Gene Set Enrichment Analysis; OLA1, Obg-like ATPase 1; p-, phosphorylated-; FDR, false discovery rate.

\section{Discussion}

P-loop NTPases mediate numerous cellular processes, such as signal translation, cell motility and cell proliferation regulation $(29,30)$. As a member of the Obg-related family, OLA1 is overexpressed in multiple types of primary human cancer, including cancer of the colon, rectum, ovary, lung, stomach and uterus $(21,22)$. In addition, OLA1 is implicated in the regulation of tumor progression in numerous types of cancer, including breast, lung and hepatocellular cancer $(17,19,20)$. However, the association between OLA1 expression and EC prognosis remains elusive. Therefore, the present study aimed to systematically elucidate the role played by OLA1 in EC progression and whether OLA1 upregulation predicted poor prognosis.

The findings of the present study suggested that OLA1 was upregulated in EC samples compared with normal samples in the transcriptome profiling data from TCGA. Similarly, immunohistochemical staining indicated that the expression levels of OLA1 protein in EC tissues were significantly upregulated. Furthermore, OLA1 expression levels were determined to be associated with clinical features, including: i) Clinical stage; ii) histological grade; iii) histological type; iv) menopause status; v) distant metastasis; and vi) cancer status. Moreover, it was found that OLA1-overexpression in patients with EC was associated with poor OS time, and OLA1 served as an independent prognostic factor. Additionally, it was determined that OLA1 promoted EC cell proliferation, migration and invasion. Taken together, these results suggested that OLA1 functioned as a potential oncogenic gene in EC and that OLA1 overexpression was a predictor of poor prognosis.

The incidence of EC is highest in developed countries, and its increasing mortality and incidence make it an essential consideration in the field of women's health (31). Almost all risk stratification systems for EC utilize a composite of clinical stage, histological type and grade (32). In the present study, univariate Cox regression analysis of TCGA data revealed that not only were age, histological grade, histological type and clinical stage associated with the OS time of patients with EC, but also distant metastasis, lymph node metastasis and cancer status. Collectively, these findings suggested that OLA1 may serve as a potential therapeutic target in EC.

The results of the current study indicated that OLA1 was significantly involved in EC-related signaling pathways, such as the 'cell cycle', the 'Wnt signaling pathway', the 'p53 signaling pathway', the 'TGF- $\beta$ signaling pathway and 'ubiquitin-mediated proteolysis'. Ding et al (11) utilized a OLA1-knockout mouse model to demonstrate that the lack of OLA1 in mouse embryos decreased cell cycle progression, which is caused by $\mathrm{p} 53$ and $\mathrm{p} 21$ accumulation. Consistent with these findings, the present study found that OLA1 may influence cell cycle progression in EC. Previous reports have established the Wnt signaling pathway as a fundamental molecular pathway, in addition to a cause of multiple tumor progression and cell function regulation (32-34). Furthermore, a previous study confirmed that in $\mathrm{EC}$ with catenin $\beta$-1 mutations, Wnt/ $\beta$-catenin 
signaling activity was enhanced (35). The current study suggests that OLA1 may regulate EC progression via the Wnt signaling pathway. Mutations in TGF- $\beta$ signaling promotes tumor emergence, including colorectal cancer, melanoma and hepatocellular carcinoma (36-38). The findings of the present study supported the evidence that OLA1 may regulate TGF- $\beta$ signaling in EC.

The ubiquitin-mediated proteolysis pathway consists of ubiquitin, ubiquitination target intracellular proteins, a three-enzyme ubiquitination complex and proteasomes, which are degradation organelles $(39,40)$. A variety of oncogenes are the targets of ubiquitination, and then regulate cancer progression $(32,33)$. In a recent study, OLA1 was recognized as a modular chaperone, binding with HSP70 to protect it from c-terminus of Hsp70-interacting protein-mediated ubiquitination and thereby inhibiting the proteolytic degradation of HSP70 (14). The findings of the present study showed that the ubiquitin-mediated proteolysis pathway may have a key role in EC progression. Further studies to explore the association between OLA1 expression and ubiquitination machinery in EC are needed.

In conclusion, the present study revealed that OLA1 acted as an oncogene in EC. Notably, it was found that high OLA1 expression levels were associated with a poorer prognosis compared with low OLA1 expression levels. Moreover, OLA1 overexpression promoted EC cell proliferation, migration and invasion, while the TGF- $\beta$, Wnt and ubiquitin-mediated proteolysis pathways may be the key pathways. This evidence suggested that OLA1 expression levels may be a potential prognostic marker in EC cases and that OLA1 may serve as a promising therapeutic target for EC treatment.

\section{Acknowledgements}

Not applicable.

\section{Funding}

The present study was funded by The Nature Science Fund of Guangdong Province (grant no. 2015A030313240) and The Medical Research Fund of Guangdong Province (grant no. A2015467).

\section{Availability of data and materials}

The datasets used and/or analyzed during the current study are available from the corresponding author upon reasonable request.

\section{Authors' contributions}

YD, AY and CX performed the experiments. HJ, WW, QW and SG designed the present study. YD, CX and AY performed the statistical analysis. YD, CX, LC and SG drafted the initial manuscript. YD and SG confirmed the authenticity of all the raw data. SG supervised the present study. All authors have read and approved the final manuscript.

\section{Ethics approval and consent to participate}

Not applicable.

\section{Patient consent for publication}

Not applicable.

\section{Competing interests}

The authors declare that they have no competing interests.

\section{References}

1. Siegel RL, Miller KD and Jemal A: Cancer statistics, 2020. CA Cancer J Clin 70: 7-30, 2020.

2. Siegel RL, Miller KD, Fuchs HE and Jemal A: Cancer statistics, 2021. CA Cancer J Clin 71: 7-33, 2021.

3. Lortet-Tieulent J, Ferlay J, Bray F and Jemal A: International patterns and trends in endometrial cancer incidence, 1978-2013. J Natl Cancer Inst 110: 354-361, 2018.

4. Connor EV and Rose PG: Management strategies for recurrent endometrial cancer. Expert Rev Anticancer Ther 18: 873-885, 2018.

5. Hamilton CA, Cheung MK, Osann K, Chen L, Teng NN, Longacre TA, Powell MA, Hendrickson MR, Kapp DS and Chan JK: Uterine papillary serous and clear cell carcinomas predict for poorer survival compared to grade 3 endometrioid corpus cancers. Br J Cancer 94: 642-646, 2006.

6. Morice P, Leary A, Creutzberg C, Abu-Rustum N and Darai E: Endometrial cancer. Lancet 387: 1094-1108, 2016.

7. Janda M, Gebski V, Brand A, Hogg R, Jobling TW, Land R, Manolitsas T, McCartney A, Nascimento M, Neesham D, et al: Quality of life after total laparoscopic hysterectomy versus total abdominal hysterectomy for stage I endometrial cancer (LACE): A randomised trial. Lancet Oncol 11: 772-780, 2010.

8. Neri M, Peiretti M, Melis GB, Piras B, Vallerino V, Paoletti AM, Madeddu C, Scartozzi M and Mais V: Systemic therapy for the treatment of endometrial cancer. Expert Opin Pharmacother 20: 2019-2032, 2019.

9. Brooks RA, Fleming GF, Lastra RR, Lee NK, Moroney JW, Son $\mathrm{CH}$, Tatebe $\mathrm{K}$ and Veneris JL: Current recommendations and recent progress in endometrial cancer. CA Cancer J Clin 69: 258-279, 2019.

10. Leipe DD, Koonin EV and Aravind L: Evolution and classification of P-loop kinases and related proteins. J Mol Biol 333: 781-815, 2003.

11. Ding Z, Liu Y, Rubio V, He J, Minze LJ and Shi ZZ: OLA1, a translational regulator of $\mathrm{p} 21$, maintains optimal cell proliferation necessary for developmental progression. Mol Cell Biol 36: 2568-2582, 2016

12. Zhang J, Rubio V, Lieberman MW and ShiZZ: OLA1, an Obg-like ATPase, suppresses antioxidant response via nontranscriptional mechanisms. Proc Natl Acad Sci USA 106: 15356-15361, 2009.

13. Jeyabal PV, Rubio V, Chen H, Zhang J and Shi ZZ: Regulation of cell-matrix adhesion by OLA1, the Obg-like ATPase 1. Biochem Biophys Res Commun 444: 568-574, 2014.

14. Mao RF, Rubio V, Chen H, Bai L, Mansour OC and Shi ZZ: OLA1 protects cells in heat shock by stabilizing HSP70. Cell Death Dis 4: e491, 2013.

15. Rosenzweig R, Nillegoda NB, Mayer MP and Bukau B: The Hsp70 chaperone network. Nat Rev Mol Cell Biol 20: 665-680, 2019.

16. Schultz A, Olorundami OA, Teng RJ, Jarzembowski J, Shi ZZ, Kumar SN, Pritchard K Jr, Konduri GG and Afolayan AJ: Decreased OLA1 (Obg-Like ATPase-1) expression drives ubiquitin-proteasome pathways to downregulate mitochondrial SOD2 (superoxide dismutase) in persistent pulmonary hypertension of the newborn. Hypertension 74: 957-966, 2019.

17. Bai L, Yu Z, Zhang J, Yuan S, Liao C, Jeyabal PV, Rubio V, Chen H, Li Y and Shi ZZ: OLA1 contributes to epithelial-mesenchymal transition in lung cancer by modulating the GSK3 $\beta /$ snail/ E-cadherin signaling. Oncotarget 7: 10402-10413, 2016.

18. Zhang JW, Rubio V, Zheng S and Shi ZZ: Knockdown of OLA1, a regulator of oxidative stress response, inhibits motility and invasion of breast cancer cells. J Zhejiang Univ Sci B 10: 796-804, 2009.

19. Liu J, Miao X, Xiao B, Huang J, Tao X, Zhang J, Zhao H, Pan Y, Wang H, Gao G and Xiao GG: Obg-like ATPase 1 enhances chemoresistance of breast cancer via activation of TGF- $\beta / \mathrm{Smad}$ axis cascades. Front Pharmacol 11: 666, 2020. 
20. Yoshino Y, Qi H, Fujita H, Shirota M, Abe S, Komiyama Y, Shindo K, Nakayama M, Matsuzawa A, Kobayashi A, et al: BRCA1-interacting protein OLA1 requires interaction with BARD1 to regulate centrosome number. Mol Cancer Res 16: 1499-1511, 2018.

21. Matsuzawa A, Kanno S, Nakayama M, Mochiduki H, Wei L, Shimaoka T, Furukawa Y, Kato K, Shibata S, Yasui A, et al: The BRCA1/BARD1-interacting protein OLA1 functions in centrosome regulation. Mol Cell 53: 101-114, 2014.

22. Takahashi M, Chiba N, Shimodaira H, Yoshino Y, Mori T, Sumii M, Nomizu T and Ishioka C: OLA1 gene sequencing in patients with BRCA1/2 mutation-negative suspected hereditary breast and ovarian cancer. Breast Cancer 24: 336-340, 2017.

23. Li Y, Liang L, Dai W, Cai G, Xu Y, Li X, Li Q and Cai S: Prognostic impact of programed cell death-1 (PD-1) and PD-ligand 1 (PD-L1) expression in cancer cells and tumor infiltrating lymphocytes in colorectal cancer. Mol Cancer 15: 55, 2016.

24. Guo S, Xiao Y, Li D, Jiang Q, Zhu L, Lin D, Jiang H, Chen W, Wang L, Liu C, et al: PGK1 and GRP78 overexpression correlates with clinical significance and poor prognosis in Chinese endometrial cancer patients. Oncotarget 9: 680-690, 2017.

25. Zhang YF, Xu QX, Liao LD, Xu XE, Wu JY, Shen J, Wu ZY,

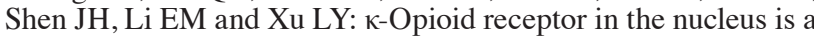
novel prognostic factor of esophageal squamous cell carcinoma. Hum Pathol 44: 1756-1765, 2013.

26. Xiao YY, Lin L, Li YH, Jiang HP, Zhu LT, Deng YR, Lin D, Chen W, Zeng CY, Wang LJ, et al: ZEB1 promotes invasion and metastasis of endometrial cancer by interacting with HDGF and inducing its transcription. Am J Cancer Res 9 2314-2330, 2019.

27. Livak KJ and Schmittgen TD: Analysis of relative gene expression data using real-time quantitative PCR and the 2(-Delta Delta C(T)) method. Methods 25: 402-408, 2001.

28. R Core Team: R: A language and environment for statistical computing. R Foundation for Statistical Computing, Vienna, Austria, 2012.

29. Chigri F, Sippel C, Kolb M and Vothknecht UC: Arabidopsis OBG-like GTPase (AtOBGL) is localized in chloroplasts and has an essential function in embryo development. Mol Plant 2: 1373-1383, 2009.
30. Maiti P, Kim HJ, Tu YT and Barrientos A: Human GTPBP10 is required for mitoribosome maturation. Nucleic Acids Res 46: 11423-11437, 2018.

31. Urick ME and Bell DW: Clinical actionability of molecular targets in endometrial cancer. Nat Rev Cancer 19: 510-521, 2019.

32. de Boer SM, Powell ME, Mileshkin L, Katsaros D, Bessette P, Haie-Meder C, Ottevanger PB, Ledermann JA, Khaw P, Colombo A, et al: Adjuvant chemoradiotherapy versus radiotherapy alone for women with high-risk endometrial cancer (PORTEC-3): Final results of an international, open-label, multicentre, randomised, phase 3 trial. Lancet Oncol 19: 295-309, 2018.

33. Flanagan DJ, Vincan E and Phesse TJ: Wnt signaling in cancer: Not a binary ON:OFF switch. Cancer Res 79: 5901-5906, 2019.

34. Kaemmerer E, Jeon MK, Berndt A, Liedtke C and Gassler N: Targeting Wnt signaling via notch in intestinal carcinogenesis. Cancers (Basel) 11: 555, 2019.

35. Nusse $\mathrm{R}$ and Clevers $\mathrm{H}$ : Wnt $/ \beta$-catenin signaling, disease, and emerging therapeutic modalities. Cell 169: 985-999, 2017.

36. Wang HX, Sharma C, Knoblich K, Granter SR and Hemler ME EWI-2 negatively regulates TGF- $\beta$ signaling leading to altered melanoma growth and metastasis. Cell Res 25: 370-385, 2015.

37. Batlle E and Massagué J: Transforming growth factor- $\beta$ signaling in immunity and cancer. Immunity 50: 924-940, 2019.

38. Jung B, Staudacher JJ and Beauchamp D: Transforming growth factor $\beta$ superfamily signaling in development of colorectal cancer. Gastroenterology 152: 36-52, 2017.

39. Hu C, Ni Z, Li BS, Yong X, Yang X, Zhang JW, Zhang D, Qin Y, Jie MM, Dong H, et al: hTERT promotes the invasion of gastric cancer cells by enhancing FOXO3a ubiquitination and subsequent ITGB1 upregulation. Gut 66: 31-42, 2017.

40. Mani A and Gelmann EP: The ubiquitin-proteasome pathway and its role in cancer. J Clin Oncol 23: 4776-4789, 2005.

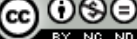

This work is licensed under a Creative Commons Attribution-NonCommercial-NoDerivatives 4.0 International (CC BY-NC-ND 4.0) License. 